\title{
Do Brain Drain and Poverty Result from Coordination Failures? *
}

\author{
David de la Croix ${ }^{1} \quad$ Frédéric Docquier ${ }^{2}$ \\ December 2009, Preliminary first draft
}

\begin{abstract}
This paper explores the interdependencies between high-skill emigration and poverty in developing countries. We build a model endogenizing human capital accumulation, migration and productivity. Depending on the magnitude of the key elasticities, the system can generate a unique equilibrium or multiple equilibria, implying that two countries sharing the same characteristics may end up in a good "low poverty-low brain drain" or bad "high poverty-high brain drain" equilibria. After identifying countryspecific parameters, we find that, for a majority of them, the observed equilibrium has higher income than the other possible ones. In 15 percent of developing countries (representing about 50 percent of small states), poverty and high brain drain are worsened by a coordination failure.
\end{abstract}

JEL Classifications: F22, O11, O15, C62

Keywords: Brain drain, Development, Multiple equilibria, Coordination failure

\footnotetext{
*Thanks are due to the Trade Team - Development Research Group of the World Bank for its financial support (World Bank contract PO. 7620076 - UPI 269656), and to Sara Salomone for assistance with various aspects of the paper. The authors acknowledge financial support from the ARC conventions on "Geographical mobility of factors" and "Sustainability", the PAI convention "Glonomics" and from the Marie-Curie research and training network TOM.

${ }^{1}$ IRES and CORE, UCLouvain, david.delacroix@uclouvain.be

${ }^{2}$ National Fund for Scientific Research (Belgium) and IRES, UCLouvain, frederic.docquier@uclouvain.be
} 


\section{Introduction}

Many observers and scholars have long considered the brain drain as a curse for origin countries in general, and for the developing world in particular. Although the new literature is less pessimistic and shows that positive spillovers can be induced by highly skilled emigration, it is fairly obvious that the brain drain affects human capital accumulation and economic performances of sending countries. It is also largely recognized that lack of economic growth and rampant poverty (going hand in hand with discriminations, political repression and lack of freedoms) is what motivate people to flee their own country.

The interdependencies between highly skilled emigration and poverty in developing countries are key to understand the process of development. They can be the source of vicious and virtuous circles linked to strategic complementarities in individual migration decisions. Indeed, when a significant brain drain movement is initiated, it might have damaging effects on the economy and induce other waves of high-skill emigration. On the contrary, when a significant movement of return operates, it gives incentives to other waves of returnees to come home.

History has shown that massive and rapid departure of high-skill people can generate hardly reversible economic damages. An interesting case is that of Iran, where pre-revolutionary economic development was rapid, though unevenly distributed among Iranians. The Iranian brain drain started with the 1978-1979 cultural revolution and was exacerbated in the early 1980s after the decision of the government to shut down Iran's higher education system. The trend continued afterwards and is seen by many observers as one of the most important exodus of talented faculty, students, and researchers. The pace of growth had slowed dramatically after the revolution and Iran is still a lower-middle income economy today. Since 2002, Iran's parliament has tried to reverse its brain drain but returns are still sporadic. A more recent example is the one observed in the former Soviet states. Many scientists and academics went abroad after independence. Russian or Moldovian trade unions report that between half a million and a million scientists and professionals have left the country since 1991. This has deteriorated the economic situation and working conditions at origin; hence, almost none of them have returned.

Breaking such vicious circles is not impossible but requires major reforms (of democratic or dictatorial types). In the 1980s, the return of educated elites and high-skill workers played a crucial role in Taiwan's economic takeoff, starting with the development of the information industry in Shinchu. The Irish case is another nice illustration of the vicious and virtuous effects of high-skill mobility. On the one hand, a wave of mass emigration of university and 
college graduates was observed in the 1980s. This brain drain sucked the marrow out of Ireland's social and economic development. On the other hand, the major fiscal reforms embraced after 1987 attracted foreign companies and investments. The Irish miracle was on track and since the late nineties, a huge movement of return migration has operated and contributed to the "Irish miracle".

The question addressed in this paper is: can a "high brain drain-high poverty" situation be the result of a coordination failure, or is the brain drain an inevitable corollary of poverty, just making the situation slightly worse? For each developing country, the data set compiled by Docquier, Lowell and Marfouk (2009) gives precise information on the human capital level of residents and emigrants abroad. In 2000, the average skill-ratio (i.e. ratio of proportion of tertiary to non-tertiary) of high-income countries was 0.243 (with values above 1 in the US and Canada). At the same year, 23 developing countries would exhibit a skill-ratio above 0.243 if all high-skill emigrants returned home. Saint Kitts and Nevis (0.866) would be close to the US and Canada; Grenada (0.611) and Dominica (0.471) and other small states would be close to Australia (0.514). Other larger countries such as the Philippines (0.333), Peru (0.309), Jamaica (0.279) or Latvia (0.271) would have more human capital than many Western European countries. If such returns were important enough to generate a rapid takeoff and eradicate incentives to emigrate, brain drain and poverty could be seen as resulting from a coordination failure. If not, the brain drain would just worsen the situation. The goal of this paper is to clarify that question using an integrated model of human capital accumulation, high-skill emigration and economic performances.

Surprisingly, the two causal links between emigration and poverty have only been separately investigated in the recent brain drain literature. On the one hand, there are many empirical studies focusing on the determinants of migration flows, usually disregarding the composition of these flows. Recently, a few recent contributions take advantage of new databases in international migration by education level to investigate the determinants of the brain drain and the skill composition of emigration flows. Docquier, Lohest and Marfouk (2007) showed that the brain drain increases with political instability and the degree of fractionalization, and decreases with the level of development at origin. Grogger and Hanson (2008) found that a simple model of income maximization can account for positive selection (higher emigration rates for the skilled) and positive sorting (positive effect of wage differentials on the share of skilled in bilateral migration). Rosenzweig (2007, 2008) used micro-data to demonstrate that there are larger per-capita numbers of foreign students in the United States from lower skill-price countries than from high skill-price countries, and host countries with higher skill prices attract the most foreign students. These studies reveal that the size and structure 
of international migration flows are clearly endogenous and depend on the economic characteristics of source and host countries. In the empirical literature, these characteristics are usually treated as exogenous (or instrumented).

On the other hand, the second strand of literature is more theoretical and focuses on the consequences of the brain drain on the welfare of those left behind. The first welfare theorem suggests that labor mobility increases the total amount of welfare at the world level. It is Pareto-improving if those gains can be appropriately redistributed among all parties concerned. When redistribution is impossible or costly, some groups or nations can be adversely affected although the size of the pie is enlarged. This argument can be decisive if there are strong complementarities between skilled and unskilled workers on the labor market or if the fiscal cost of education is large and totally supported by residents at origin. Bhagwati and Hamada (1974) or McCullock and Yellen $(1975,1977)$ were the first to stress the negative impact of the brain drain for developing countries. The brain drain was seen as a zero sum game with the rich countries getting richer and the poor countries getting poorer. Later, relying on the existence of externalities linked to human capital, the endogenous growth framework offered an appropriate environment to demonstrate that any loss of human capital can be detrimental for the remaining households (e.g., Miyagiwa, 1991, Haque and Kim, 1995). On the contrary, an influential newer literature (Mountford, 1997; Stark et al., 1998; and Beine et al., 2001) suggests that the emigration of skilled workers can increase sending-country educational investments or induce other positive feedback effects. In particular, prospects of emigration to countries where skills are rewarded more generously can lead not only to increased investment in skills before migration (ex-ante), but also to a larger higher-educated domestic population after migration (ex-post). ${ }^{1}$ A problem with this 'brain gain' framework is that it usually ignores the endogeneity of the emigration probability.

In the paper, we build bridges between these two strands of literature and develop a richer model allowing for coordination failure. The reduced form of our model can be summarized by two equations (one endogenizing the level of development and one endogenizing human capital accumulation). Under certain conditions, the system generates a multiple equilibria. Multiplicity implies that two countries sharing particular characteristics may end up in a good (low poverty, low brain drain) or bad (high poverty, high brain drain) equilibrium. The properties of the equilibria need not be identical across nations. It is very likely to depend on the exogenous characteristics of nations and on educational policies (education

\footnotetext{
${ }^{1}$ Beine et al. (2008) estimated the net effect of the brain drain for each developing country and region. They found that the brain drain stimulates human capital accumulation among residents in some countries. It appears that the countries experiencing a positive net effect (the 'winners') generally combine low levels of human capital (below 5\%) and low skilled migration rates (below 20\%), whereas the 'losers' are typically characterized by high skilled migration rates and/or high domestic enrollment rates in higher education.
} 
and fiscal policies). For example, small countries geographically or culturally close to the rich world are likely to exhibit stronger elasticities of migration to economic environment than large, landlocked and remote countries. Our numerical experiments reveal that 22 countries (including 20 small states with less than 2 million inhabitants, Jamaica and Haiti) are suffering from coordination failure. In these countries, a positive shock or better expectations could generate a virtuous circle of rapid returns and more prosperity. Other small states and larger states are on their good equilibrium, even Russia or Iran which are losing large absolute numbers of tertiary educated (475,095 for Russia and 315,640 for Iran). Given their size, these numbers represent relatively small proportions of their educated labor force (2.4 percent in Russia and 14.7 in Iran). These proportions are too low to be the fruit of coordination problems.

The remainder of the paper is organized as following. Section 2 describes our theoretical framework and derive the conditions under which multiplicity is obtained. Our benchmark model follows the traditional/pessimistic literature on brain drain and development, i.e. considers the brain drain as detrimental for human capital accumulation. In Section 3, we use macrodata to calibrate the benchmark model on developing countries by identifying the country-specific characteristics. This allows us to characterize the type of equilibrium observed in all developing countries. In Section 4, we analyze the robustness of our results to identifying assumption and account for the recent/optimistic brain gain literature. Finally, Section 5 concludes.

\section{Theory}

Our model depicts a developing economy with endogenous technology, highly skilled emigration and human capital accumulation. It is based on a minimal set of functions and assumptions.

Each developing country is characterized by a linear production function with two perfectly substitutable inputs, high-skill and low-skill labor $\left(H_{t}\right.$ and $\left.L_{t}\right)$, and an endogenous productivity factor $\lambda_{t}$ :

$$
Y_{t}=\lambda_{t}\left(\bar{\omega} L_{t}+H_{t}\right)
$$

where $\bar{\omega}<1$ is the average productivity of non high-skill workers (i.e. workers with low and medium education level) relatively to high-skill workers. Hence, high-skill workers' income is equal to $\lambda_{t}$ whereas low-skill workers earn $\bar{\omega} \lambda_{t}$. The assumption of perfect substitutability of the two types of labor implies that the skill premium will not depend on the amount of 
efficient labor of both types. With imperfect substitution, countries with low number of skill persons should display a very high skill premium, which is not observed in the data.

We consider a Lucas-type technological externality (see Lucas, 1988) and assume that the scale productivity factor is a concave static function of the skill-ratio in the resident labor force. Hence, we have

$$
\lambda_{t}=A \gamma^{t} k_{t}^{\alpha} \quad \text { with } k_{t} \equiv \frac{H_{t}}{L_{t}}
$$

where $A$ is a country fixed effect, $\gamma^{t}$ is a time trend which is common to all developing and developed countries $(\gamma>1)$, and $\alpha \in(0,1)$ is the elasticity of productivity to the skill-ratio. Preferences are represented by an indirect utility function assumed to be logarithmic in income. Low-skill individuals are immobile across countries whereas high-skill individuals have the choice between staying in their country or emigrating to a richer industrialized country. Migration is permanent and we disregard the links between migrants and their origin country (such as remittances or diaspora externalities). Productivity or income at destination is exogenous and denoted by $\bar{\lambda}_{t}=\bar{A} \gamma^{t}$ with $\bar{A}>0$. We do not endogenize $\bar{A}$ as a function of the skill-ratio at destination, implicitly assuming that high-skill immigration from each developing country is too small to affect productivity. Hence, our model is only relevant to the analysis of developing countries.

Migration induces a heterogenous moving cost for individual $i$, denoted by $\varepsilon_{i}$, which must be substracted from the utility level. Obviously, migration is optimal for individual $i$ if and only if

$$
\ln \bar{A}-\varepsilon_{i} \geq \ln A+\alpha \ln k_{t} .
$$

Hence, at time t, all individuals with migration costs below a critical value find it optimal to emigrate. The critical value is given by

$$
\varepsilon_{t} \equiv \ln \bar{A}-\ln A-\alpha \ln k_{t}
$$

The threshold $\varepsilon_{t}$ is decreasing with the skill-ratio $k_{t}$ and characterizes the income differential (in logs) with high-income destinations. At the margin, the size of migration costs for the individual who is indifferent between migrating or staying is equal to the income differential. It can reasonably be used as an index of poverty (or underdevelopment) of the country.

Migration costs are distributed according to a cumulative distribution function $G(\varepsilon)$ with location parameter $m$ and dispersion parameter $b$. Hence, $G_{t}=G\left(\varepsilon_{t}\right)$ measures the proportion of high-skill emigrants at time $t$, i.e. the rate of brain drain. We impose the following assumption on $G(\varepsilon)$ : 
Assumption 1 The distribution function of migration costs satisfies ${ }^{2}$

$$
G^{\prime}(x)=o(\exp (-x / \alpha)) \text { when } x \rightarrow+\infty
$$

As it will appear later, Assumption 1 will be a sufficient condition to obtain multiplicity of equilibria and coordination failures. It means that $G^{\prime}(\varepsilon)$ goes to 0 much faster than $\exp (-\varepsilon / \alpha)$ as $\varepsilon$ goes to infinity. This assumption would be verified in the case where the cumulative distribution function $G(\varepsilon)$ reaches one for a value of $x \in \mathbb{R}$. It is also automatically satisfied if $G(\varepsilon)$ is a normal distribution with positive mean, or if $G(\varepsilon)$ is a Gumbel distribution with positive location. If $G(\varepsilon)$ is a logistic distribution, Assumption 1 also holds provided that the scale of the distribution is larger than $\alpha$.

At this stage, it is useful to distinguish $k_{t}$, the skill-ratio in the ex-post (or after-migration) resident labor force and $z_{t}$, the skill-ratio in the ex-ante (or before-migration) native labor force. Since only educated workers migrate at a rate $G\left(\varepsilon_{t}\right)$, we obviously have

$$
k_{t}=z_{t}\left[1-G\left(\varepsilon_{t}\right)\right]
$$

The dynamics of our economy is governed by human capital accumulation. For simplicity, it is assumed that high-skill workers educate all their children whereas low-skill workers only educate a fraction $q \in(0,1)$ of them. Denoting the skilled population $Z^{s}$ and the low-skill population $Z^{u}$, their dynamics is given by

$$
\begin{aligned}
& Z_{t+1}^{s}=n^{s} Z_{t}^{s}\left[1-G\left(\varepsilon_{t}\right)\right]+q n^{u} Z_{t}^{u} \\
& Z_{t+1}^{u}=(1-q) n^{u} Z_{t}^{u}
\end{aligned}
$$

Where $n^{s}$ and $n^{u}$ denote number of children. Denoting by $n=n^{s} / n^{u}$ the relative number of children in high-skill households (in proportion of the number observed in low-skill households), we have

$$
z_{t+1}=Z_{t+1}^{s} / Z_{t+1}^{u}=\frac{1-G\left(\varepsilon_{t}\right)}{1-q} n z_{t}+\frac{q}{1-q}
$$

Our model is made of equations (1) to (5). In these equations, we consider that parameters $\bar{A}>0, \alpha \in(0,1)$ and $n \in(0,1)$ are identical across developing countries. The other exogenous variables are country-specific characteristics. Hence, a developing country can be identified as following:

\footnotetext{
${ }^{2} o()$ means little-o of (Landau notation).
} 
Definition $1 A$ developing country is a quadruple $\Omega=\{A, q, m, b\}$ representing the technological fixed effect $(A>0)$, the fraction of educated children in low-skill households $(q \in(0,1))$, the location and the scale parameters of the distribution of migration cost $(m \in \mathbb{R}, b>0)$.

The parameters and country characteristics determine the level and the time path of the two main endogenous variables, the index of poverty $\varepsilon_{t}$ and the ex-ante skill-ratio $z_{t}$. Indeed, when trajectories for $\varepsilon_{t}$ and $z_{t}$ are known, it is straightforward to compute the trajectories of the other endogenous variables $\left(\lambda_{t}, Y_{t}, k_{t}\right)$. In other words, the system (1)-to-(5) can easily be reduced into a two-variable system. We have:

Definition 2 Given an initial skilled to unskilled ratio $\bar{z}_{0}>0$, an inter-temporal equilibrium with migration is a vector of skilled to unskilled ratios $\left\{z_{t}\right\}_{t \geq 0} \in \mathbb{R}_{+}^{\infty}$ and a vector of poverty indexes $\left\{\varepsilon_{t}\right\}_{t \geq 0} \in \mathbb{R}^{\infty}$ such that $z_{0}=\bar{z}_{0}$ and $\forall t \geq 0$ :

$$
\begin{aligned}
\varepsilon_{t} & =\ln \bar{A}-\ln A\left[\left(1-G\left(\varepsilon_{t}\right)\right) z_{t}\right]^{\alpha} \equiv f\left(\varepsilon_{t}, z_{t}\right), \\
z_{t+1} & =\frac{q}{1-q}+\frac{1-G\left(\varepsilon_{t}\right)}{1-q} n z_{t} \equiv h\left(\varepsilon_{t}, z_{t}\right) .
\end{aligned}
$$

Equation (6) is a static incentive compatibility condition. For a given ex-ante skill-ratio $z_{t}$, it characterizes the combination(s) of poverty index $\varepsilon_{t}$ and high-skill emigration rate $G\left(\varepsilon_{t}\right)$ compatible with the technology level and households' decisions at time $t$. Equation (7) is dynamic and characterizes human capital accumulation. For a given ex-ante skill-ratio and poverty index at time $t$, it gives the ex-ante skill-ratio at time $t+1$.

We have the following result:

Proposition 1 Under Assumption 1, there exists a threshold $\hat{z}$ such that, in equilibrium, $z_{t}>\hat{z} \forall t \geq 0$.

Proof. We proof the proposition using a Reductio ad absurdum. Suppose we have an equilibrium with, at some date $s, z_{s}<\hat{z}$. We will show that there would be no $\varepsilon_{s}$ satisfying $\varepsilon_{s}-f\left(\varepsilon_{s}, z_{s}\right)=0$, that is, Equation (6).

Solving (6) for $z_{s}$ we obtain

$$
z_{s}=\Phi \frac{\exp \left(-\varepsilon_{s} / \alpha\right)}{1-G\left(\varepsilon_{s}\right)} \equiv \phi\left(\varepsilon_{s}\right) \quad \text { with } \quad \Phi=\left(\frac{\bar{A}}{A}\right)^{1 / \alpha} .
$$


The function $\phi(\varepsilon)$ is continuous. Its limit when $\varepsilon \rightarrow-\infty$ is equal to $+\infty$. Under Assumption 1 , its limit when $\varepsilon \rightarrow+\infty$ is equal to $+\infty$. It therefore has a global minimum at some $\hat{\varepsilon}$. This global minimum should satisfy:

$$
\phi^{\prime}(\varepsilon)=0 \Leftrightarrow 1-G(\varepsilon)-\alpha G^{\prime}(\varepsilon)=0
$$

Let us define $\hat{z}=\phi(\hat{\varepsilon})$. There is no $\varepsilon \in \mathbb{R}$ such that $\phi(\varepsilon)<\hat{z}$. As a consequence there is no $\varepsilon \in \mathbb{R}$ solving (6) for $z<\hat{z}$. Hence, when $z_{s}<\hat{z},(6)$ could not hold and this cannot be an equilibrium.

We now introduce a second assumption, which is by now way crucial for the following results, but greatly simplifies the analysis.

Assumption 2 The distribution function of migration costs is such that there is a unique $\varepsilon$ satisfying

$$
1-G(\varepsilon)-\alpha G^{\prime}(\varepsilon)=0
$$

This implies the following lemma:

Lemma 1 Under Assumptions 1 and 2 For any level $z>\hat{z}$ there exists two values of $\varepsilon$, $s^{+}\left(z_{t}\right)>s^{-}\left(z_{t}\right)$, such that the incentive constraint $\varepsilon=f(\varepsilon, z)$ holds.

Proof. Consider the function $z=\phi(\varepsilon) \Leftrightarrow \varepsilon-f(\varepsilon, z)=0$. We have seen in the above proof that it goes from $+\infty$ to $+\infty$ as $\varepsilon$ goes from $-\infty$ to $+\infty$, and has a global minimum at the point $(\hat{\varepsilon}, \hat{z})$. Assumption 2 implies that this function changes slope only once, at its minimum. As a consequence, for any $z_{t}>\hat{z}$, there are two values of $\varepsilon_{t}$ solving $\varepsilon_{t}-f\left(\varepsilon_{t}, z_{t}\right)=0$. Let us denote these two solutions $s^{+}\left(z_{t}\right)>s^{-}\left(z_{t}\right)$.

The solution $s^{+}\left(z_{t}\right)$ corresponds to a high poverty index and high brain drain: the ex-post skill ratio $k_{t}$ is much below the ex-ante level $z_{t}$ and the productivity level is low. Solution $s^{-}\left(z_{t}\right)$ corresponds to a low poverty index and low brain drain: the ex-post skill ratio $k_{t}$ is close to the ex-ante level $z_{t}$ and the productivity level is high.

At each $t$, there are therefore two values of $z_{t+1}$ compatible with Equations (6)-(7). The dynamics can be written as:

$$
z_{t+1}=\left\{\begin{array}{c}
h\left(s^{+}\left(z_{t}\right), z_{t}\right) \\
\text { or } \\
h\left(s^{-}\left(z_{t}\right), z_{t}\right)
\end{array}\right.
$$


If these two values are above $\hat{z}$, we can compute four values of $z_{t+2}$ using (6)-(7), etc... Hence there is a possibility for an infinite number of equilibria, starting from the initial condition $\bar{z}_{0}$.

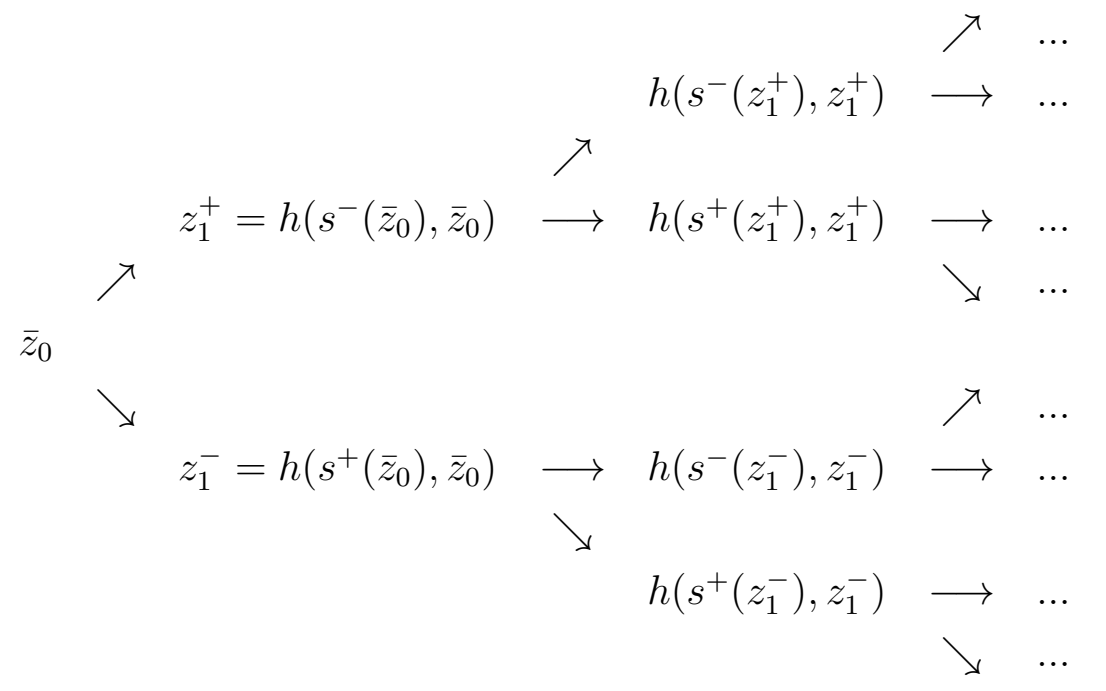

In order to describe more precisely the possible long-run outcomes, we list here some properties of the two functions $h\left(s^{+}\left(z_{t}\right), z_{t}\right)$ and $h\left(s^{-}\left(z_{t}\right), z_{t}\right)$.

- $h\left(s^{+}(\hat{z}), \hat{z}\right)=h\left(s^{-}(\hat{z}), \hat{z}\right)=h(\hat{\varepsilon}, \hat{z})$

- since $\phi_{\varepsilon}^{\prime}<0$ for $\varepsilon<\hat{\varepsilon}$, and $s^{-}\left(z_{t}\right)$ is a decreasing function, the function $h\left(s^{-}\left(z_{t}\right), z_{t}\right)$ is increasing in $z_{t}$;

- $\operatorname{since} s^{+}\left(z_{t}\right)>s^{-}\left(z_{t}\right), h\left(s^{-}\left(z_{t}\right), z_{t}\right)>h\left(s^{+}\left(z_{t}\right), z_{t}\right)$;

- Consider the $\varepsilon$ implicitly defined by $z=\phi(\varepsilon)$. When $z$ tends to $+\infty$, both $\varepsilon=+\infty$ $(G(\varepsilon)=1)$ and $\varepsilon=-\infty(G(\varepsilon)=0)$ satisfy this relation, and hence $\lim _{z \rightarrow \infty} s^{-}\left(z_{t}\right)=$ $-\infty$ and $\lim _{z \rightarrow \infty} s^{+}\left(z_{t}\right)=+\infty$.

- When $z$ tends to infinity, the function $h\left(s^{-}\left(z_{t}\right), z_{t}\right)$ tends to the oblique asymptote obtained under

$$
G(\varepsilon)=0: \frac{q}{1-q}+\frac{n}{1-q} z
$$

- When $z$ tends to infinity, the function $h\left(s^{+}\left(z_{t}\right), z_{t}\right)$ tends to the horizontal asymptote obtained under $G(\varepsilon)=1$ :

$$
\frac{q}{1-q}
$$


Figure 1: Dynamic correspondence

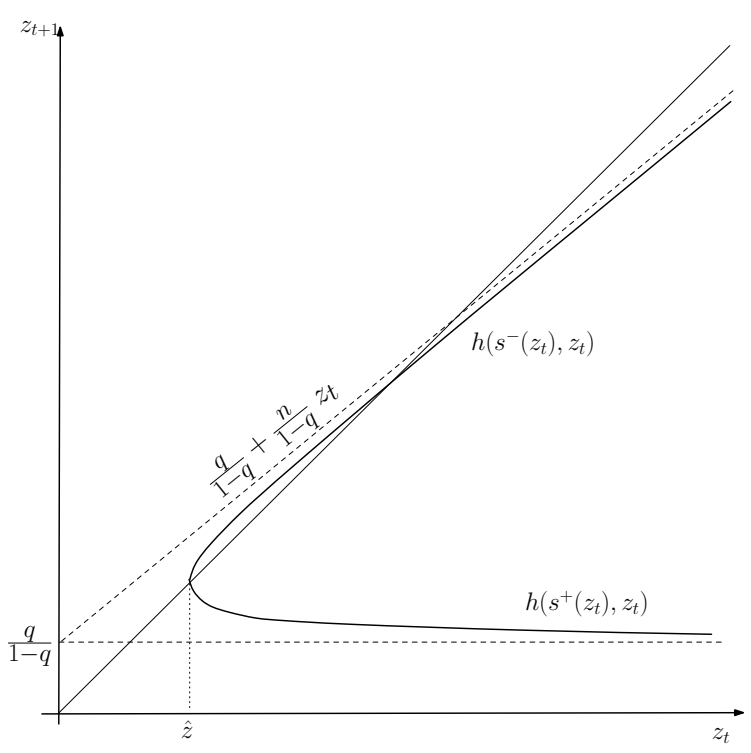

Figure 1 represents a dynamic correspondence which satisfies the properties derive above. The following proposition summarizes the conditions for the existence of equilibrium.

Proposition 2 Under Assumptions 1 and 2 an inter-temporal equilibrium exists under the following conditions.

When $h(\hat{\varepsilon}, \hat{z})>\hat{z}$, if $z_{0}>\hat{z}$, an equilibrium exists.

When $h(\hat{\varepsilon}, \hat{z})<\hat{z}$,

- if $h\left(s^{-}(z), z\right)<z$ forall $z>0$, no equilibrium exists.

- if there exists $\tilde{z}>0$ such that $h\left(s^{-}(\tilde{z}), \tilde{z}\right)<$ tildez and if $\bar{z}_{0} \geq \underline{z}$, where $\underline{z}$ is the smallest steady state of the dynamics $z_{t+1}=h\left(s^{-}\left(z_{t}\right), z_{t}\right)$, an equilibrium exists.

\section{Proof.}

When $h(\hat{\varepsilon}, \hat{z})>\hat{z}, z_{0}>\hat{z}$ ensures that there exists at least one inter-temporal equilibrium satisfying the monotone dynamics $z_{t+1}=h\left(s^{-}\left(z_{t}\right), z_{t}\right)$.

When $h(\hat{\varepsilon}, \hat{z})<\hat{z}$, If $h\left(s^{-}(z), z\right)<z$ forall $z>0$, the function $h\left(s^{-}\left(z_{t}\right), z_{t}\right)<z_{t}$ lays below the forty-five degrees line for all $z_{t}$, all the possible dynamics starting from $\bar{z}_{0}$ are decreasing, and there will be inevitably some date $T$ at which $z_{t}<\hat{z}$. Hence, there exists no inter-temporal equilibrium. 
Figure 2: Multiple equilibria starting from $\bar{z}_{0}$
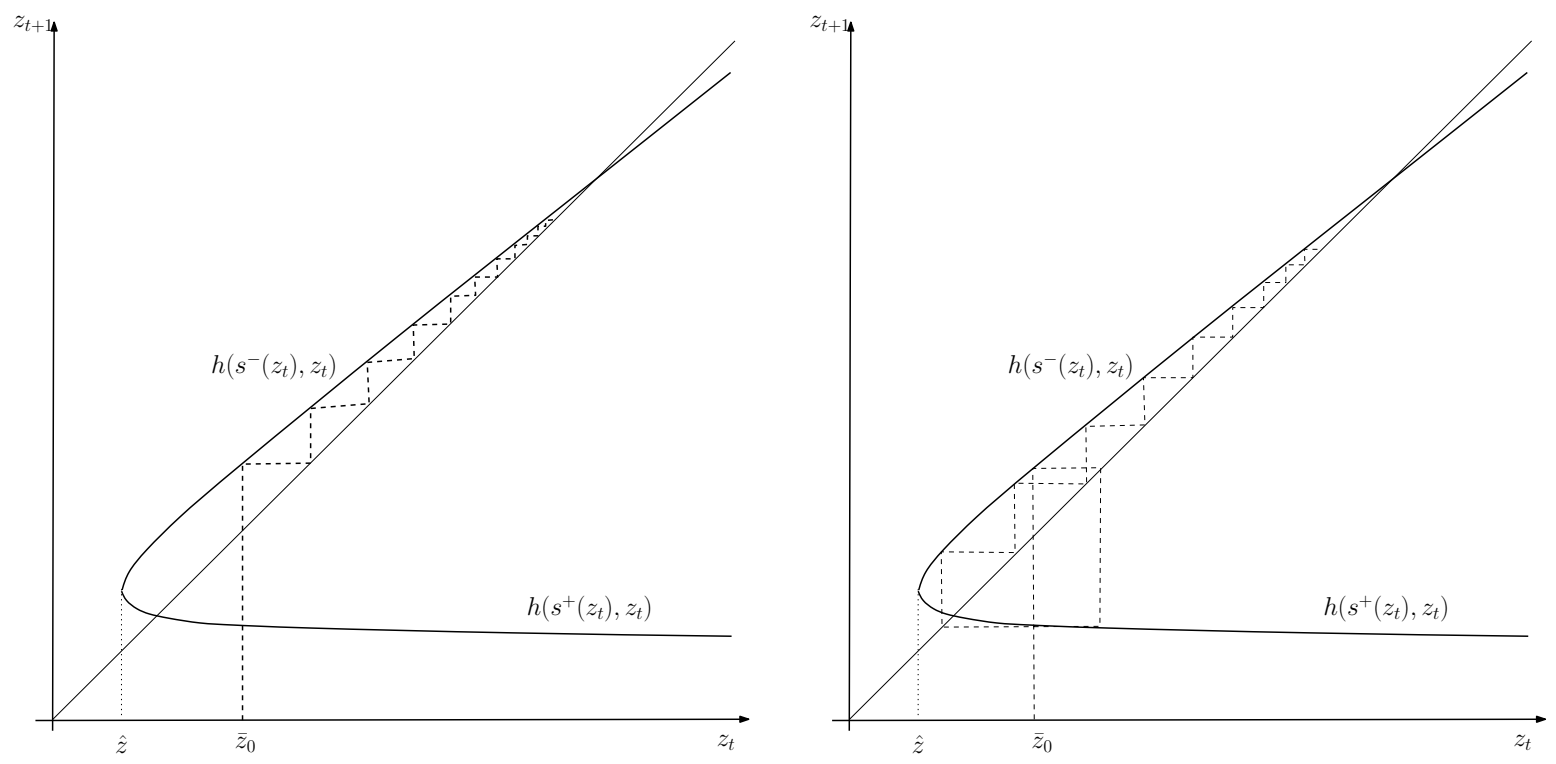

When $h(\hat{\varepsilon}, \hat{z})<\hat{z}$, if there exists $\tilde{z}>0$ such that $h\left(s^{-}(\tilde{z}), \tilde{z}\right)<$ tildez, the function $h\left(s^{-}\left(z_{t}\right), z_{t}\right)$ cuts the forty-five degrees line at some point; let us denote $\underline{z}$ the smallest steady state of the dynamics $z_{t+1}=h\left(s^{-}\left(z_{t}\right), z_{t}\right)$. Provided that $\bar{z}_{0} \geq \underline{z}$, there exists at least one inter-temporal equilibrium (see De la Croix and Michel (2002), Proposition 3.6, for a similar case in the context of pension systems).

Obviously, as soon as one equilibrium exists, an infinite number of equilibria exist. Figure 2 gives an example of two equilibria starting from $z_{0}$.

The key condition separating the two cases of Proposition $2, h(\hat{\varepsilon}, \hat{z})>\hat{z}$, can be expressed explicitly as a condition on the productivity parameter $A$ in the case where the function $G(\varepsilon)$ is a Gumbel distribution. The Gumbel distribution is a continuous probability distribution belonging to the family of generalized extreme value distributions. The Gumbel is referred to as the type I extreme value distribution. It is traditionally used in migration models where utility includes an iid random component (varying between individuals and countries of destination). As shown in McFadden (1984), when the iid component follows an extreme value distribution, the probability that an individual emigrate to a particular destination is governed by a simple logit expression. Our choice is not guided by this objective. The Gumbel is used here for its mathematical tractability (it can be easily inverted).

$$
G(\varepsilon)=1-e^{-e^{\frac{\varepsilon-m}{b}}}
$$


Using this functional form for $G()$, we can solve the inequality $h(\hat{\varepsilon}, \hat{z})<\hat{z}$ for the parameter $A$ :

$$
A<\left(\frac{\bar{A}^{\frac{1}{\alpha}} e^{-\frac{m}{\alpha}}\left(e^{b / \alpha}(1-q)-n\right)\left(\frac{b}{\alpha}\right)^{-\frac{b}{\alpha}}}{q}\right)^{\alpha} \Leftrightarrow h(\hat{\varepsilon}, \hat{z})<\hat{z}
$$

Hence, the no-existence of equilibrium can only arise when productivity is small enough, given the other parameters.

We now derive some comparative static results in the context of a Gumbel distribution of migration costs. Results can be obtained for the point $p=\{\hat{z}, h(\hat{\varepsilon}, \hat{z})\}$ using the results of Proposition 1:

$$
\hat{z}=\Phi\left(\frac{b}{\alpha}\right)^{-b / \alpha} e^{(b-m) / \alpha},
$$

and $\hat{\varepsilon}=m+b \ln \left(\frac{b}{\alpha}\right)$. We first compute $h(\hat{\varepsilon}, \hat{z})$ which gives:

$$
h(\hat{\varepsilon}, \hat{z})=\frac{q}{1-q}+\frac{n}{1-q} \Phi\left(\frac{b}{\alpha}\right)^{-b / \alpha} e^{-m / \alpha}
$$

Using the partial derivatives of $\hat{z}$ and $h(\hat{\varepsilon}, \hat{z})$ with respect to the parameters of interest, $q$, $n, m$, and $\Phi$ we get:

$$
\begin{gathered}
\frac{\partial p}{\partial q}=\left\{0, \frac{e^{-\frac{m}{\alpha}} n \Phi\left(\frac{b}{\alpha}\right)^{-\frac{b}{\alpha}}+1}{(1-q)^{2}}\right\} \\
\frac{\partial p}{\partial n}=\left\{0, \frac{e^{-\frac{m}{\alpha}}\left(\frac{b}{\alpha}\right)^{-\frac{b}{\alpha}} \Phi}{1-q}\right\} \\
\frac{\partial p}{\partial m}=\left\{-\frac{e^{\frac{-\log \left(\frac{b}{\alpha}\right) b+b-m}{\alpha} \Phi}}{\alpha},-\frac{e^{-\frac{m}{\alpha}} n\left(\frac{b}{\alpha}\right)^{-\frac{b}{\alpha}} \Phi}{(1-q) \alpha}\right\} \\
\frac{\partial p}{\partial \Phi}=\left\{e^{\frac{-\log \left(\frac{b}{\alpha}\right) b+b-m}{\alpha}}, \frac{e^{-\frac{m}{\alpha}} n\left(\frac{b}{\alpha}\right)^{-\frac{b}{\alpha}}}{1-q}\right\}
\end{gathered}
$$

The two first expressions indicate that when $q$ or $n$ increases, the point $p$ moves vertically upward. The conditions for existence would be unchanged in the case where $h(\hat{\varepsilon}, \hat{z})>\hat{z}$ ( $\hat{z}$ is unchanged) or easier to fulfill in the case where $h(\hat{\varepsilon}, \hat{z})<\hat{z}$ as the smallest steady state $\underline{z}$ would be lowered. If the slope of the function does not change too much (which is what simulations indicate), it would also imply that the high steady state would be higher. Concerning the low steady state, it would be also increase in Case 1, but decrease in Case 2 
(i.e. when it is certainly unstable). This implies that education policies and/or population policies increasing $n$ increase the steady state level of skill ratio $z$ as soon as it is locally stable.

From the last two expressions, it appears that increasing location $m$ or decreasing $\Phi$ (i.e. increasing productivity $A$ ) move the point $p$ unambiguously to the South West. Hence it enlarges the scope for existence of equilibrium ( $\hat{z}$ is lower). As far as steady state are concerned, $m$ modifies deeply the shape of the function.

\section{Quantitative assessment}

The goal of this section is to calibrate common and country-specific parameters, and simulate the configuration of equilibria observed in each developing countries. We use data on highly skilled emigration stocks/rates and on the labor force by education level from Appendix 1. Three levels of education are distinguished, individuals with upper-secondary education, those with less than upper-secondary and those with post-secondary education. High-skill workers are those in the latter category. Data on GDP are from the Penn World Tables. Our calibration is based on the year 2000 and can be summarized in Table 1.

Table 1: Calibrated parameters - Summary

\begin{tabular}{llll}
\hline Prm. & Definition & Source & Value \\
\hline Global parameters & & \\
$\alpha$ & Elasticity of productivity to human cap & Regressions 1990-00 & 0.28 \\
$\bar{A}$ & Productivity in developed countries & Mean of 9 main dest & 64.2 \\
$n$ & Fertility differential (as a ratio) & Kremer \& Chen (1999) & 0.605 \\
Developing countries specific parameters & & \\
$A$ & Technological fixed effect & Eq (11) & \\
$q$ & Prop of educ children in low-skill hous. & Eq (12) & \\
$m$ & Location of the mig cost distrib. & Eq (14) & \\
$b$ & Scale of the mig cost distrib & Eq $(13)$ & \\
\hline
\end{tabular}

\subsection{Calibration of common parameters}

Remember we consider that parameters $\alpha \in(0,1)$ (the elasticity of productivity to the skillratio), $\bar{A}>0$ (productivity in leading countries), and $n \in(0,1)$ (the fertility differential between high-skill and low-skill workers) are identical across developing countries. 
To calibrate $\alpha$, we use data on the labor force by education level. The numbers of high-skill, low-skill and medium-skill resident workers $\left(H_{j, t}, L_{j, t}^{1}, L_{j, t}^{2}\right)$ are available for each country $j$ at time $t$ from the Docquier, Lowell and Marfouk's database. High-skill workers $\left(H_{j, t}\right)$ are those with post-secondary education. In the low-skill group, we distinguish workers with upper secondary education $\left(L_{j, t}^{1}\right)$ and those with less than upper secondary $\left(L_{j, t}^{2}\right)$. The skill-ratio in the resident labor force is given by

$$
k_{j, t}=\frac{H_{j, t}}{L_{j, t}^{1}+L_{j, t}^{2}}
$$

We use equation (1) and assume that the relative productivity of low-skill and medium-skill workers are equal to $\omega^{1}$ and $\omega^{2}$. We use $\omega_{1}=.6$ and $\omega_{2}=.25$. Given GDP data, the productivity scale factor of country $j$ is obtained as a residual:

$$
\lambda_{j, t}=\frac{Y_{j, t}}{\omega^{1} L_{j, t}^{1}+\omega^{2} L_{j, t}^{2}+H_{j, t}}
$$

We use data for 1990 and 2000 and normalize $\gamma^{00}$ to unity and $\gamma^{90}=\bar{A}_{90} / \bar{A}_{00}$ in equation (2). Regressing $\ln \lambda_{j, t} / \gamma^{t}$ on $\ln k_{j, t}$ gives an estimate for $\alpha$. Using a large sample of developing countries (142 observations), we obtain an elasticity of 0.277 , significant at 1 percent (the $\mathrm{R}$-squared of the regression is equal to 0.24 ). This elasticity will be used in the benchmark simulation. Note that using a larger sample of 195 developing and developed countries, we obtain an elasticity of 0.447 (the R-squared is equal to 0.38 ). This larger value will be used in the robustness analysis.

The calibrated productivity in leading countries, $\bar{A}$, is equal to $\bar{\lambda}_{2000}$. The value $\bar{\lambda}_{2000}$ is the weighted average of the productivity scale factors obtained for 9 leading countries (Australia, Canada, France, Germany, Japan, Korea, Saudi Arabia, United Kingdom and the United States). The weights are the country's shares in the total labor force of the group. We obtain $\bar{A}=64.18$.

Using data from Kremer and Chen (1999), we compute the fertility differential for 1985-89 for 26 developing countries. The correlation between country-specific fertility differentials and human capital of women is low (14 percent) so that we can consider the fertility differential as independent on the level of development. The average fertility differential between highskill (more than 10 years of education) and low-skill workers (less than 10 years of schooling) amounts to 0.605 . We use this value for $n$ in all countries. 


\subsection{Calibration of country-specific characteristics}

As stated in Definition 1, each developing country $j$ is characterized by a quadruple of parameters $\Omega_{j}=\left\{A_{j}, q_{j}, m_{j}, b_{j}\right\}$ representing the technological fixed effect $\left(A_{j}>0\right)$, the fraction of educated children in low-skill households $\left(q_{j} \in(0,1)\right)$, the location and the scale parameters of the distribution of migration cost $\left(m_{j} \in \mathbb{R}, b_{j}>0\right)$.

The calibration of the technological fixed effect $A_{j}$ is done at the year 2000. We use equation (2) and the estimated value for $\alpha$. We have:

$$
\ln A_{j}=\ln \lambda_{2000, j}-0.277 \times \ln k_{2000, j}
$$

where $k_{2000, j}$ and $\lambda_{2000, j}$ are given by equations (9) and (10).

To calibrate $q_{j}$, we use the dynamic equation (5) and consider that one period represents 25 years. The proportion of high-skill workers in the resident labor force (ex-post or aftermigration labor force), $k_{j, 75}$, can be obtained for 1975 from Defoort (2008), herself relying on different sources (mostly Barro and Lee, 2001). The proportion of high-skill workers in the native labor force (ex-ante or before-migration labor force), $z_{j, 00}$, can be obtained for 2000 by adding resident and emigrated workers by education level and computing the structure of the native labor force. Data on human capital and emigrants to OECD destinations are taken from Docquier, Lowell and Marfouk (2009). Generally speaking, the skill level of immigrants in non-OECD countries is expected to be very low, except in a few countries such as South Africa, the member states of the Gulf Cooperation Council, some Eastern Asian countries such as Singapore or Hong Kong. Focusing on OECD destinations, the database should capture a large fraction of the worldwide educated migration (a portion between 80 and 90 percent), but is also likely to underestimate the number of emigrants from several developing countries located at the neighborhood of important destinations. Here, we collect or estimate data from non-OECD destinations to expand the coverage of the above studies. We double the number of destinations, adding 31 non OECD destinations, and compute more accurate measures of the brain drain for all the world countries and characterize "South-South" and "North-South" emigration patterns. As expected, the inclusion of non OECD countries such as the Gulf states, South Africa, Singapore or Ivory Coast has a impact on the brain drain neighboring countries. Our method is explained in Appendix 1. Equation (5) can be rewritten as

$$
z_{j, 00}=\frac{n k_{j, 75}}{1-q_{j}}+\frac{q_{j}}{1-q_{j}}
$$


Solving for $q_{j}$ yields:

$$
q_{j}=\frac{z_{j, 00}-n k_{j, 75}}{1+z_{j, 00}}
$$

For all countries excepted Saint Kitts and Nevis $(q=0.4574)$, we have $q<1-n$ so that the the oblique asymptote on Figure 1 has a slope lower than one.

Finally, we have to specify a functional form for the distribution of migration costs and estimate its parameters. In the benchmark analysis, migration costs are assume to follow a Gumbel distribution with country-specific parameters $m \in \mathbb{R}$ (location) and $b>0$ (scale). The Logistic or Normal distributions will be used in the robustness analysis. The mean and variance of the distribution is related to the location and scale parameter as follows: mean $=m-\gamma b$ where $\gamma$ is the Euler's constant (0.577), and variance $=\pi^{2} b^{2} / 6$. Inverting $G(\varepsilon)$ gives $\frac{\varepsilon_{j}-m_{j}}{b_{j}}=G^{-1}\left(G_{j}\right)=\ln \left[-\ln \left(1-G_{j}\right)\right]$.

Since this function has two country-specific parameters, we need to observations to calibrate them. For each developing country, we can easily compute $\varepsilon_{j} \equiv \ln \bar{A}-\ln A-\alpha \ln k_{j}$ and observe $G_{j}$ in 2000 . This gives a first pair $\left(\varepsilon_{j}, G_{j}\right)$ which can be used to identify the parameters of the distribution. We need another reference pair $\left(\varepsilon_{\min }, G_{\min }\right)$ which characterize the hypothetical brain drain rate $G_{\min }$ obtained with low poverty level $\varepsilon_{\min }$. In the benchmark, we assume that at the level of the US income $\left(\varepsilon_{U S}\right)$, the brain drain of each developing country would equal the US brain drain $\left(G_{U S}\right)$. This allows us to calibrate $\left(m_{j}, b_{j}\right)$ as following:

$$
\begin{aligned}
b_{j} & =\frac{\varepsilon_{j}-\varepsilon_{U S}}{G^{-1}\left(G_{j}\right)-G^{-1}\left(G_{U S}\right)} \\
m_{j} & \equiv \varepsilon_{j}-b_{j} \times G^{-1}\left(G_{j}\right)
\end{aligned}
$$

The coefficients $\left(m_{j}, b_{j}\right)$ capture the mean of migration costs and the average sensitivity of migration to income differentials. The higher $m_{j}$, the lower the propensity to emigrate. The higher $b_{j}$, the lower the sensitivity of emigration rates to income. Moreover, given (14) and $G^{-1}\left(G_{j}\right)<0, m_{j}$ and $b_{j}$ are perfectly collinear The recent empirical literature on international migration reveals that the propensity to emigrate is a function of the distance to OECD countries, language spoken, country size and cultural links with potential destinations, etc. A simple correlation analysis reveals that our migration costs are positively correlated with population size (0.32) and distance to OECD (0.20), and negatively correlated with dummies capturing former colonial ties (-0.43), knowledge of English (-0.26) and being a oil producing country (-0.10).

Consequently, the mean of the distribution is low in small states and small islands and in 
regions such as Central America and the Caribbean, Northern and Southern Africa, the new members of the European Union and countries located in the neighborhood of the Persian Gulf states. On the contrary, $m_{j}$ is high in the ex-Soviet block, in South-East and Eastern Asia, in many countries of South America and Central Africa.

\subsection{Benchmark configurations}

The calibration of country-specific parameters allows us to characterize the equilibrium configuration observed in each developing country. In particular, we are interested in computing the number of steady state equilibria, checking their stability, and comparing the observed equilibrium to the alternative one when multiplicity occurs. Our numerical exercise is conducted on 144 developing countries and gives the following results.

All countries except Croatia and Saint Kitts and Nevis and are characterized by 2 locally stable steady state equilibria, labeled $\left(z^{-}, G^{-}\right)$for and $\left(z^{+}, G^{+}\right)$. The good "low-braindrain" steady state equilibrium is $\left(z^{-}, G^{-}\right)$. In Croatia, the observed equilibrium in 2000 is on the "good branch" of the dynamic correspondence and converging to $\left(z^{-}, G^{-}\right)$provided it remains on this branch; the alternative steady state equilibrium $\left(z^{+}, G^{+}\right)$is unstable. As stressed above, in Saint Kitts and Nevis the oblique asymptote on Figure 1 has a slope higher than one implying that dynamics can be possibly unbounded.

Large countries exhibit high migration costs. Considering the 105 countries with more than 2 million inhabitants, the observed equilibrium in $2000\left(z_{00}, G_{00}\right)$ is on the good "branch" in the vast majority of cases. Only two cases are on the bad "branch". Jamaica exhibits a brain drain of 84.7 percent. Remaining on the bad branch, its brain drain would reach 86.3 percent in 2025 and 86.2 percent at the steady state. Moving on the good branch would reduce the long-run brain drain to 3.0 percent. Haiti exhibits a brain drain of 83.4 percent. Remaining on the bad branch, its brain drain would reach 86.0 percent in 2025 and 85.8 percent at the steady state. Moving on the good branch would reduce the long-run brain drain to 18.7 percent.

The 103 other countries with population above 2 million are on the good branch. The bad equilibrium is usually a trivial equilibrium with more than 95 percent of brain drain and high poverty. We have 14 exceptions for which the bad equilibrium involves a brain drain below 90 percent (See Table 2). In these countries, a major adverse shock could have damaging long-run effects on the economy if it gives rise to a sudden and uncoordinated emigration of the highly skilled. These are Dominican Republic (5.5 vs 85.6) ${ }^{3}$, El Salvador (10.0 vs 83.6),

\footnotetext{
${ }^{3}$ Numbers in parentheses are $G_{s s}^{-}$and $G_{s s}^{+}$for the 14 countries.
} 
Table 2: Large states with risk of coordination failure

\begin{tabular}{l|cccc|cccc}
\hline \hline Country & $z_{00}^{-}$ & $G_{00}^{-}$ & $z_{25}^{-}$ & $G_{25}^{-}$ & $z_{s s}^{-}$ & $G_{s s}^{-}$ & $z_{s s}^{+}$ & $G_{s s}^{+}$ \\
\hline Czech Republic & 0.133 & 0.090 & 0.181 & 0.056 & 0.283 & 0.029 & 0.109 & 0.878 \\
Dominican Republic & 0.219 & 0.227 & 0.320 & 0.131 & 0.629 & 0.055 & 0.221 & 0.856 \\
El Salvador & 0.176 & 0.323 & 0.243 & 0.204 & 0.434 & 0.100 & 0.181 & 0.836 \\
Guatemala & 0.080 & 0.244 & 0.112 & 0.164 & 0.174 & 0.100 & 0.078 & 0.899 \\
Hungary & 0.158 & 0.134 & 0.210 & 0.081 & 0.336 & 0.037 & 0.138 & 0.778 \\
Lebanon & 0.214 & 0.455 & 0.283 & 0.248 & 0.591 & 0.084 & 0.242 & 0.750 \\
Macedonia & 0.236 & 0.320 & 0.277 & 0.272 & 0.373 & 0.204 & 0.180 & 0.877 \\
Malaysia & 0.098 & 0.174 & 0.141 & 0.075 & 0.244 & 0.025 & 0.107 & 0.723 \\
Mexico & 0.150 & 0.156 & 0.213 & 0.098 & 0.360 & 0.051 & 0.137 & 0.896 \\
Namibia & 0.059 & 0.294 & 0.068 & 0.248 & 0.085 & 0.193 & 0.047 & 0.826 \\
Nicaragua & 0.145 & 0.324 & 0.177 & 0.264 & 0.241 & 0.196 & 0.120 & 0.891 \\
Papua New Guinea & 0.021 & 0.289 & 0.030 & 0.153 & 0.049 & 0.074 & 0.024 & 0.808 \\
Tunisia & 0.074 & 0.143 & 0.107 & 0.086 & 0.171 & 0.047 & 0.071 & 0.898 \\
Uruguay & 0.163 & 0.120 & 0.214 & 0.075 & 0.336 & 0.035 & 0.136 & 0.792 \\
\hline \hline
\end{tabular}

Guatemala (10.0 vs 90.0), Lebanon (8.4 vs 75.0), Macedonia (20.4 vs 87.7) Malaysia (2.5 vs 72.3), Mexico (5.1 vs 89.6), Namibia (19.3 vs 82.6), Nicaragua (19.6 vs 89.1), Papua New Guinea (7.5 vs 80.8 ), Tunisia (4.7 vs 89.8), Uruguay (3.5 vs 79.2), Czech Republic (2.9 vs 87.8) and Hungary.(3.7 vs 77.8$)$.

Regarding the 42 small states with less than 2 million inhabitants, the configuration is mixed. On the one hand, 22 small states are on the good branch $\left(z^{-}, G^{-}\right)$in 2000 . Table 3 lists these countries and give their equilibrium in 2025 and at the steady state, provided that they remain on the good branch. Except Solomon islands, the brain drain is expected to decrease in these countries; the average emigration rate in this group amounts to 29.6 percent in 2000 and will reach 18.3 percent in the long-run (23.0 percent in 2025). On the other hand, 20 small states are on the bad branch $\left(z^{+}, G^{+}\right)$in 2000. Table 4 shows that the emigration rate will increase in all these countries; the average rate equals 69.5 percent in 2000 and will reach 75.9 percent in the long-run (76.9 percent in 2025).

For other countries with population above 2 million, we predict a significant decrease in the brain drain, provided that they remain on the same branch of the dynamic path. Exceptions are Jamaica and Haiti (on the bad branch), Pakistan and Nigeria. The average emigration rate is equal to 19.1 percent in 2000 . It will reach 15.5 percent in 2025 and 12.6 percent in the long-run. 
Table 3: Small states on the good path

\begin{tabular}{l|cccc|cccc}
\hline \hline Country & $z_{00}^{-}$ & $G_{00}^{-}$ & $z_{25}^{-}$ & $G_{25}^{-}$ & $z_{s s}^{-}$ & $G_{s s}^{-}$ & $z_{s s}^{+}$ & $G_{s s}^{+}$ \\
\hline Bahamas & 0.338 & 0.259 & 0.507 & 0.043 & 1.474 & 0.002 & 0.441 & 0.622 \\
Botswana & 0.045 & 0.084 & 0.068 & 0.050 & 0.108 & 0.028 & 0.043 & 0.948 \\
Comoros & 0.026 & 0.231 & 0.035 & 0.195 & 0.048 & 0.165 & 0.023 & 0.997 \\
Djibouti & 0.058 & 0.039 & 0.080 & 0.034 & 0.117 & 0.028 & 0.045 & 1.000 \\
East Timor & 0.065 & 0.222 & 0.082 & 0.203 & 0.104 & 0.185 & 0.050 & 1.000 \\
Equatorial Guinea & 0.053 & 0.220 & 0.076 & 0.067 & 0.133 & 0.017 & 0.064 & 0.650 \\
Estonia & 0.278 & 0.111 & 0.419 & 0.066 & 0.858 & 0.027 & 0.248 & 0.925 \\
Gabon & 0.143 & 0.049 & 0.224 & 0.026 & 0.404 & 0.012 & 0.135 & 0.953 \\
Gambia & 0.013 & 0.682 & 0.013 & 0.650 & 0.014 & 0.612 & 0.012 & 0.857 \\
Guinea-Bissau & 0.014 & 0.289 & 0.018 & 0.260 & 0.023 & 0.237 & 0.012 & 1.000 \\
Kiribati & 0.034 & 0.558 & 0.039 & 0.479 & 0.048 & 0.403 & 0.032 & 0.885 \\
Lesotho & 0.014 & 0.248 & 0.019 & 0.197 & 0.027 & 0.159 & 0.013 & 0.991 \\
Marshall Islands & 0.135 & 0.429 & 0.163 & 0.355 & 0.218 & 0.271 & 0.121 & 0.882 \\
Micronesia & 0.148 & 0.487 & 0.176 & 0.376 & 0.258 & 0.240 & 0.146 & 0.788 \\
Namibia & 0.059 & 0.294 & 0.068 & 0.248 & 0.085 & 0.193 & 0.047 & 0.826 \\
Nauru & 0.053 & 0.721 & 0.059 & 0.604 & 0.074 & 0.475 & 0.055 & 0.835 \\
Sao Tome and Principe & 0.043 & 0.275 & 0.060 & 0.228 & 0.083 & 0.192 & 0.041 & 0.997 \\
Slovenia & 0.191 & 0.126 & 0.234 & 0.044 & 0.372 & 0.007 & 0.199 & 0.426 \\
Solomon Islands & 0.020 & 0.260 & 0.019 & 0.271 & 0.018 & 0.288 & 0.010 & 0.941 \\
Swaziland & 0.055 & 0.195 & 0.080 & 0.061 & 0.140 & 0.016 & 0.066 & 0.673 \\
Tuvalu & 0.043 & 0.652 & 0.048 & 0.539 & 0.062 & 0.415 & 0.044 & 0.824 \\
Vanuatu & 0.084 & 0.084 & 0.111 & 0.073 & 0.154 & 0.063 & 0.061 & 1.000 \\
\hline \hline
\end{tabular}


Table 4: Small States on the bad path

\begin{tabular}{l|cccc|cccc}
\hline \hline Country & $z_{00}^{+}$ & $G_{00}^{+}$ & $z_{25}^{+}$ & $G_{25}^{+}$ & $z_{s s}^{+}$ & $G_{s s}^{+}$ & $z_{s s}^{-}$ & $G_{s s}^{-}$ \\
\hline Antigua and Barbuda & 0.457 & 0.704 & 0.553 & 0.781 & 0.541 & 0.774 & 3.258 & 0.002 \\
Barbados & 0.363 & 0.627 & 0.460 & 0.727 & 0.453 & 0.721 & 1.907 & 0.000 \\
Belize & 0.284 & 0.656 & 0.345 & 0.753 & 0.336 & 0.743 & 1.128 & 0.009 \\
Cape Verde & 0.059 & 0.828 & 0.065 & 0.849 & 0.065 & 0.848 & 0.161 & 0.007 \\
Cyprus & 0.318 & 0.353 & 0.399 & 0.502 & 0.394 & 0.494 & $\mathrm{NA}$ & $\mathrm{NA}$ \\
Dominica & 0.471 & 0.641 & 0.608 & 0.755 & 0.591 & 0.746 & 3.885 & 0.000 \\
Fiji & 0.206 & 0.628 & 0.236 & 0.775 & 0.223 & 0.738 & 0.466 & 0.145 \\
Grenada & 0.611 & 0.843 & 0.682 & 0.865 & 0.679 & 0.864 & 15.495 & 0.000 \\
Guyana & 0.388 & 0.894 & 0.413 & 0.904 & 0.411 & 0.904 & 1.966 & 0.032 \\
Malta & 0.168 & 0.585 & 0.193 & $\mathrm{NA}$ & 0.193 & 0.641 & $\mathrm{NA}$ & $\mathrm{NA}$ \\
Mauritius & 0.091 & 0.419 & 0.115 & 0.579 & 0.113 & 0.567 & 0.233 & 0.000 \\
Palau & 0.258 & 0.838 & 0.285 & $\mathrm{NA}$ & 0.285 & 0.854 & $\mathrm{NA}$ & $\mathrm{NA}$ \\
Saint Kitts \& Nevis & 0.866 & 0.844 & 0.994 & 0.866 & 0.991 & 0.866 & $\mathrm{NA}$ & $\mathrm{NA}$ \\
Saint Lucia & 0.152 & 0.687 & 0.164 & 0.736 & 0.162 & 0.729 & 0.377 & 0.050 \\
Saint Vinc \& Grenadines & 0.309 & 0.846 & 0.326 & 0.857 & 0.325 & 0.856 & 1.291 & 0.004 \\
Samoa & 0.291 & 0.735 & 0.323 & 0.814 & 0.313 & 0.796 & 0.722 & 0.171 \\
Seychelles & 0.187 & 0.572 & 0.235 & 0.688 & 0.231 & 0.680 & 0.619 & 0.000 \\
Suriname & 0.271 & 0.660 & 0.320 & 0.759 & 0.310 & 0.745 & 0.933 & 0.032 \\
Tonga & 0.313 & 0.757 & 0.346 & 0.815 & 0.338 & 0.804 & 0.897 & 0.125 \\
Trinidad and Tobago & 0.226 & 0.790 & 0.250 & 0.814 & 0.249 & 0.813 & 0.812 & 0.000 \\
\hline \hline
\end{tabular}

In sum, according to our model, 22 countries (including 20 small states) suffer from a coordination failure. By repatriating highly skilled natives working abroad, they would rapidly reach a productivity level inciting high-skill workers to stay and generating more human capital accumulation. This represents 15 percent of the sample, but 47.6 percent of countries with less than 2 million inhabitants. Hence, coordination failure leading to massive highly-skilled emigration is an important problem when migration costs are low.

\section{Robustness}

In this section, we analyze to robustness of our results to the identifying assumptions made in the previous section and to the brain gain mechanism, which implies the endogeneity of $q_{j}$. 


\subsection{Robustness to identifying assumptions}

Our benchmark numerical exercise is based on three major identifying assumptions:

- The elasticity of productivity to human capital is estimated on a sample of developing countries. We obtain $\underline{\alpha}=.277$. Using the full sample of 195 countries, the elasticity goes up to $\bar{\alpha}=.447$. A priori, a higher $\alpha$ can reinforce the possibility of multiple equilibria since it increases the sensitivity of economic performances to high-skill emigration.

- Individual migration costs are assumed to follow a Gumbel cumulative distribution function. In this section, we consider two other distributions characterized by a location and dispersion parameters, the Logistic and the Normal distributions.

- The identification of the parameters of the migration costs' distribution relies on the hypothesis that at the US income level $\left(\varepsilon_{U S}=-0.013\right)$, developing countries would have the same brain drain than the US (i.e. $G_{U S}=0.005$ ). Since most cases of coordination failure are obtained for small states, one may expect the minimal brain drain of these countries to exceed the US level at high income. In this section, we identify the parameters of the distribution on the Qatar income and brain drain levels $\left(\varepsilon_{Q a t}=-0.382\right.$ and $\left.G_{Q a t}=0.023\right)$, Qatar being a small states with about 745,000 inhabitants according to our definition.

In Table 4, we identify the cases of coordination failures in 12 scenarios: 2 values for $\alpha$ $\times 3$ distributions $\times 2$ values for $\left(\varepsilon_{\min }, G_{\min }\right)$. Unsurprisingly, the number of coordination failures increases when $\bar{\alpha}=.447$, and decreases when the parameters of the migration costs' distribution are calibrated on Qatar. The use of the Normal distribution (and Logistic to a lower extent) also reduces the number of countries on the bad branch.

For 7 countries, a coordination failure is obtained in all scenarios. These are Cape Verde, Grenada, Palau, St Kitts and Nevis, Si Vincent and Grenadines, Malta and, Trinidad and Tobago. For 7 other countries, a coordination default is obtained under 10 scenarios: Belize, Dominica, Guyana, Jamaica, Seychelles, Antigua and Barbuda, and Barbados. To a lower extent, Mauritius and Cyprus are also robust cases.

\subsection{Robustness to "brain gain" channel}

A recent wave of brain drain research has emerged since the mid-1990s around the idea that highly skilled emigration generates positive feedback effects for sending countries. Some 
Figure 3: Robustness to identifying assumptions

\begin{tabular}{|c|c|c|c|c|c|c|c|c|c|c|c|c|}
\hline & \multicolumn{6}{|c|}{ Calibration on USA } & \multicolumn{6}{|c|}{ Calibration on Qatar } \\
\hline & \multicolumn{2}{|c|}{ Gumbel } & \multicolumn{2}{|c|}{ Logistic } & \multicolumn{2}{|c|}{ Normal } & \multicolumn{2}{|c|}{ Gumbel } & \multicolumn{2}{|c|}{ Logistic } & \multicolumn{2}{|c|}{ Normal } \\
\hline & $\underline{\alpha}$ & $\bar{\alpha}$ & $\underline{\alpha}$ & $\bar{\alpha}$ & $\underline{\alpha}$ & $\bar{\alpha}$ & $\underline{\alpha}$ & $\bar{\alpha}$ & $\underline{\alpha}$ & $\bar{\alpha}$ & $\underline{\alpha}$ & $\bar{\alpha}$ \\
\hline Coordination failure & 22 & 28 & 20 & 29 & 16 & 22 & 15 & 22 & 7 & 17 & 7 & 17 \\
\hline Belize & $\mathrm{x}$ & $\mathrm{x}$ & $\mathrm{x}$ & $\mathrm{x}$ & $\mathrm{x}$ & $\mathrm{x}$ & $\mathrm{x}$ & $\mathrm{x}$ & & $\mathrm{x}$ & & $\mathrm{x}$ \\
\hline Cape Verde & $\mathrm{x}$ & $\mathrm{x}$ & $\mathrm{x}$ & $\mathrm{x}$ & $\mathrm{x}$ & $\mathrm{x}$ & $\mathrm{x}$ & $\mathrm{x}$ & $\mathrm{x}$ & $\mathrm{x}$ & $\mathrm{x}$ & $\mathrm{x}$ \\
\hline Dominica & $\mathrm{x}$ & $\mathrm{x}$ & $\mathrm{x}$ & $\mathrm{x}$ & $\mathrm{x}$ & $\mathrm{x}$ & $\mathrm{x}$ & $\mathrm{x}$ & & $\mathrm{x}$ & & $\mathrm{x}$ \\
\hline Fiji & $\mathrm{x}$ & $\mathrm{x}$ & $?$ & $\mathrm{x}$ & & $\mathrm{x}$ & & $\mathrm{x}$ & & & & \\
\hline Gambia & & $\mathrm{x}$ & $?$ & $\mathrm{x}$ & & & & & & & & \\
\hline Grenada & $\mathrm{x}$ & $\mathrm{x}$ & $\mathrm{x}$ & $\mathrm{x}$ & $\mathrm{x}$ & $\mathrm{x}$ & $\mathrm{x}$ & $\mathrm{x}$ & $\mathrm{x}$ & $\mathrm{x}$ & $\mathrm{x}$ & $\mathrm{x}$ \\
\hline Guyana & $\mathrm{x}$ & $\mathrm{x}$ & $\mathrm{x}$ & $\mathrm{x}$ & $\mathrm{x}$ & $\mathrm{x}$ & $\mathrm{x}$ & $\mathrm{x}$ & & $\mathrm{x}$ & & $\mathrm{x}$ \\
\hline Haiti & $\mathrm{x}$ & $\mathrm{x}$ & $?$ & $\mathrm{x}$ & & $\mathrm{x}$ & $\mathrm{x}$ & $\mathrm{x}$ & & & & \\
\hline Jamaica & $\mathrm{x}$ & $\mathrm{x}$ & $\mathrm{x}$ & $\mathrm{x}$ & $\mathrm{x}$ & $\mathrm{x}$ & $\mathrm{x}$ & $\mathrm{x}$ & & $\mathrm{x}$ & & $\mathrm{x}$ \\
\hline Kiribati & & & $?$ & $\mathrm{x}$ & & & & & & & & \\
\hline Lebanon & & $\mathrm{x}$ & $\mathrm{x}$ & $\mathrm{x}$ & & & & & & & & \\
\hline Mauritius & $\mathrm{x}$ & $\mathrm{x}$ & $\mathrm{x}$ & $\mathrm{x}$ & $\mathrm{x}$ & $\mathrm{x}$ & & $\mathrm{x}$ & & $\mathrm{x}$ & & $\mathrm{x}$ \\
\hline Micronesia & & $\mathrm{x}$ & $?$ & $\mathrm{x}$ & & & & & & & & \\
\hline Nauru & & $\mathrm{x}$ & $?$ & $\mathrm{x}$ & & & & & & & & \\
\hline Palau & $\mathrm{x}$ & $\mathrm{x}$ & $\mathrm{x}$ & $\mathrm{x}$ & $\mathrm{x}$ & $\mathrm{x}$ & $\mathrm{x}$ & $\mathrm{x}$ & $\mathrm{x}$ & $\mathrm{x}$ & $\mathrm{x}$ & $\mathrm{x}$ \\
\hline Saint Kitts \& Nevis & $\mathrm{x}$ & $\mathrm{x}$ & $\mathrm{x}$ & $\mathrm{x}$ & $\mathrm{x}$ & $\mathrm{x}$ & $\mathrm{x}$ & $\mathrm{x}$ & $\mathrm{x}$ & $\mathrm{x}$ & $\mathrm{x}$ & $\mathrm{x}$ \\
\hline Saint Lucia & $\mathrm{x}$ & $\mathrm{x}$ & $\mathrm{x}$ & $\mathrm{x}$ & & $\mathrm{x}$ & & $\mathrm{x}$ & & $\mathrm{x}$ & & $\mathrm{x}$ \\
\hline Saint Vinc \& Gren & $\mathrm{x}$ & $\mathrm{x}$ & $\mathrm{x}$ & $\mathrm{x}$ & $\mathrm{x}$ & $\mathrm{x}$ & $\mathrm{x}$ & $\mathrm{x}$ & $\mathrm{x}$ & $\mathrm{x}$ & $\mathrm{x}$ & $\mathrm{x}$ \\
\hline Samoa & $\mathrm{x}$ & $\mathrm{x}$ & $?$ & $\mathrm{x}$ & & $\mathrm{x}$ & & $\mathrm{x}$ & & & & \\
\hline Seychelles & $\mathrm{x}$ & $\mathrm{x}$ & $\mathrm{x}$ & $\mathrm{x}$ & $\mathrm{x}$ & $\mathrm{x}$ & $\mathrm{x}$ & $\mathrm{x}$ & & $\mathrm{x}$ & & $\mathrm{x}$ \\
\hline Suriname & $\mathrm{x}$ & $\mathrm{x}$ & $\mathrm{x}$ & $\mathrm{x}$ & & $\mathrm{x}$ & & $\mathrm{x}$ & & & & \\
\hline Tonga & $\mathrm{x}$ & $\mathrm{x}$ & & $\mathrm{x}$ & & $\mathrm{x}$ & & $\mathrm{x}$ & & & & \\
\hline Tuvalu & & $\mathrm{x}$ & & $\mathrm{x}$ & & & & & & & & \\
\hline Antigua and Barbuda & $\mathrm{x}$ & $\mathrm{x}$ & $\mathrm{x}$ & $\mathrm{x}$ & $\mathrm{x}$ & $\mathrm{x}$ & $\mathrm{x}$ & $\mathrm{x}$ & & $\mathrm{x}$ & & $\mathrm{x}$ \\
\hline Bahamas & & $\mathrm{x}$ & $\mathrm{x}$ & $\mathrm{x}$ & & & & & & & & \\
\hline Barbados & $\mathrm{x}$ & $\mathrm{x}$ & $\mathrm{x}$ & $\mathrm{x}$ & $\mathrm{x}$ & $\mathrm{x}$ & $\mathrm{x}$ & $\mathrm{x}$ & & $\mathrm{x}$ & & $\mathrm{x}$ \\
\hline Cyprus & $\mathrm{x}$ & $\mathrm{x}$ & $\mathrm{x}$ & $\mathrm{x}$ & $\mathrm{x}$ & $\mathrm{x}$ & & $\mathrm{x}$ & & $\mathrm{x}$ & & $\mathrm{x}$ \\
\hline Malta & $\mathrm{x}$ & $\mathrm{x}$ & $\mathrm{x}$ & $\mathrm{x}$ & $\mathrm{x}$ & $\mathrm{x}$ & $\mathrm{x}$ & $\mathrm{x}$ & $\mathrm{x}$ & $\mathrm{x}$ & $\mathrm{x}$ & $\mathrm{x}$ \\
\hline Trinidad and Tobago & $\mathrm{x}$ & $\mathrm{x}$ & $\mathrm{x}$ & $\mathrm{x}$ & $\mathrm{x}$ & $\mathrm{x}$ & $\mathrm{x}$ & $\mathrm{x}$ & $\mathrm{x}$ & $\mathrm{x}$ & $\mathrm{x}$ & $\mathrm{x}$ \\
\hline
\end{tabular}


feedback effects, which were already underlined in the early literature (remittances, return migration, and knowledge and business networks), have given rise to an increasingly important empirical literature which contributes to the emergence of a more balanced view of the brain drain. In addition, high-skill migration prospects can foster domestic enrolment in education in developing countries, raising the possibility for a brain drain to be beneficial to the source country.

The latter hypothesis can be introduced in our model by endogenzing $q$ as a function of the current brain drain (brain gain literature) or lagged brain drain (remittances). A simple regression shows a positive relationship between $q_{j}$ and $G_{j}$. We have $q_{j}=q_{j}^{c}+0.095 G_{g}$ where the estimated coefficient is highly significant (p-value much below 1 percent). This confirms the conclusion of the recent brain gain literature according to which migration prospects stimulate human capital investments. The country-specific constant can be obtained as a residual.

[Implications to be completed]

\section{Conclusion}

When skilled households expect their home country to have low productivity and to be poorly governed, the most mobile of them will move to a better place. This can only reinforce the bad features present at home. On the contrary, if people expect high productivity and good governance, they will stay, promoting thereby high productivity and good governance.

Such vicious or virtuous circles seem to arise very naturally when one takes into account the relationship between brain drain and development level in the home country. We accordingly built a model which is open to the possibility of multiple equilibria. We derived theoretical conditions under which they effectively arise. Identifying country-specific parameters in the data, we classified countries into different categories depending on whether multiple equilibria are possible, and whether the observed situation might be one of high brain drain and high poverty.

For a majority of countries, the observed equilibrium has higher income than the other possible ones. In 15 percent of developing countries (representing about 50 percent of small states), poverty and high brain drain are worsened by a coordination failure. By repatriating

highly skilled natives working abroad, they would reach a productivity level inciting high-skill workers to stay and generating more human capital accumulation. 


\section{$6 \quad$ References}

Beine, M., F. Docquier and H. Rapoport (2001), "Brain drain and economic growth: theory and evidence", Journal of Development Economics 64 (1), 275-89.

Beine, M., F. Docquier and H. Rapoport (2008), "Brain drain and human capital formation in developing countries: winners and losers", Economic Journal 118 (4), 631-52.

Bhagwati, J.N. et K. Hamada (1974), "The brain drain, international integration of markets for professionals and unemployment", Journal of Development Economics 1 (1), 19-42.

Defoort, C. (2008), "Tendances de long terme en migrations internationales: analyse à partir de 6 pays receveurs", Population-E 63, pp. 285-318.

De la Croix D. and P. Michel (2002), A Theory of Economic Growth. Dynamics and Policy in Overlapping Generations, Cambridge University Press.

Docquier, F., O. Lohest, A. Marfouk (2007), "Brain drain in developing countries", World Bank Economic Review 21, 193-218.

Docquier, F., B. L. Lowell et A. Marfouk (2009), A gendered assessment of the brain drain, Population and Development Review, forthcoming.

Grogger, J. et G. H. Hanson (2008), "Income maximization and the selection and sorting of international migrants", NBER Working Paper No. 13821.

Haque, N. U and S. Kim (1995), "Human capital flight: impact of migration on income and growth", IMF Staff Papers 42 (3), 577-607.

Kremer, M. and D. Chen (1999), "Income-Distribution Dynamics with Endogenous Fertility," American Economic Review 89(2), 155-160.

Lucas, R.E. (1988), "On the mechanics of economic development", Journal of Monetary Economics 22 (3), 3-42.

McCullock, R. and J.T. Yellen (1975), "Consequences of a tax on the brain drain for unemployment and income inequality in Less Developed Countries", Journal of Development Economics 2 (3), 249-64.

McCullock, R. and J.T. Yellen (1977): Factor mobility, regional development and the distribution of income, Journal of Political Economy 85 (1), 79-96.

McFadden, D. (1984), "Econometric analysis of qualitative response models", in: Z. Griliches and M. Intriligator, eds., Handbook of Econometrics, Volume 2, Amsterdam. Elsevier/NorthHolland.Grogger and Hanson (2008) 
Miyagiwa, K. (1991), "Scale economies in education and the brain drain problem", International Economic Review 32 (3), 743-59.

Mountford, A. (1997), "Can a brain drain be good for growth in the source economy?", Journal of Development Economics 53 (2), 287-303.

Rosenzweig, M.R. (2007), "Higher Education and International Migration in Asia: Brain Circulation", paper presented at the World Bank Annual Regional Conference, Beijing, january 2007.

Rosenzweig, M.R. (2008), "The global migration of skill", paper presented in the conference on "Migration and Development", Lille - June 2008.

Stark, O., C. Helmenstein and A. Prskawetz (1998), "Human capital depletion, human capital formation, and migration: a blessing or a 'curse'?", Economics Letters 60 (3), 363-7. 